Title:

\title{
Integrating Hydrogen Generation and Storage in a Novel Compact Electrochemical System Based on Metal Hydrides
}

Authors \& affiliations:

C.M. Rangel ${ }^{1 *}$, V. R. Fernandes ${ }^{1}$, Y. Slavkov ${ }^{2}$, L. Bozukov ${ }^{2}$

${ }^{1}$ INETI, Electrochemistry of Materials Unit / DMTP, Paço do Lumiar, 22 1649-038 Lisboa Portugal

${ }^{2}$ Labtech Ltd. Mladost 1, Bld.25/A, Sofia 1784, Bulgaria carmen.rangel@ineti.pt

* Corresponding author

\begin{abstract}
:
A novel electrochemical system has been developed which integrates hydrogen production, storage and compression in only one device, at relatively low cost and high efficiency.

The development of efficient and reliable energy storage systems based on hydrogen technology represents a challenge to seasonal storage based on renewable hydrogen. State of the art renewable energy generation systems include separate units such as electrolyser, hydrogen storage vessel and a fuel cell system for the conversion of $\mathrm{H}_{2}$ back into electricity, when required. In this work, a compact unit integrating production and storage is proposed.

The developed prototype comprises a six electrode cell assembly using an $\mathrm{AB}_{5}$ type metal hydride and Ni plates as counterelectrodes, in a $35 \mathrm{wt} \% \mathrm{KOH}$ solution.

During charging, hydrogen is absorbed in the metal hydride and corresponding oxygen is conveyed out of the system. Conversely, in the case of discharging hydrogen stored in the metal hydride is released to an external $\mathrm{H}_{2}$ storage. In the present prototype, released hydrogen was delivered into the hydrogen storage up to a pressure of 15 Bar.

Metal hydride electrodes with chemical composition $\mathrm{LaNi}_{4 \cdot 3} \mathrm{Co}_{0.4} \mathrm{Al}_{0 \cdot 3}$ were prepared by high frequency vacuum melting followed by high temperature annealing at $1000^{\mathrm{O}} \mathrm{C}$ during 8 hours. X-Ray phase analysis showed typical hexagonal structure and no traces of other intermetallic compounds belonging to the La-Ni phase diagram. Thermodynamic study has been performed in a Sieverts type of apparatus produced by Labtech. Int.

During cycling, charging was run at $40 \mathrm{~A}$ at cell voltages of $1.7 \mathrm{~V}$ for two hours which corresponds to $\mathrm{C} / 2$ charging time. Hydrogen was released by applying a constant current of $40 \mathrm{~A}$ for two hours until cell voltage rise from 0.5 to $1.7 \mathrm{~V}$, at the end of the processes. The process was studied in-situ using a gas chromatograph from Agilent.

It is anticipated that the device will be integrated as a combined hydrogen generator and storage unit in a stand alone system associated to a $1 \mathrm{~kW}$ fuel cell.
\end{abstract}

Do NOT write outside the boxes. Any text that is not in the boxes may be deleted. 